\title{
Metaphor Studies from the Perspective of Critical Discourse Analysis: A Case Study of Business Acquisition
}

\author{
Song Guo \\ School of Foreign Languages, Tianjin University of Commerce, 300134, China
}

\begin{abstract}
Although Critical Discourse Analysis (CDA) has been developing rapidly, it faces strong criticism from scholars due to its lack of attention to the cognitive aspects of discourse. As a fundamental cognitive tool to conceptualize the world, metaphor plays a vital role in constructing social reality. Providing a particular perspective of viewing the reality, metaphor forms an important part of ideology. Therefore, we should not only focus on its cognitive function, but also its pragmatic and ideological function. The paper argues that metaphor research can be integrated into CDA and enrich the latter's theoretical framework and analytic tools.
\end{abstract}

Index Terms — critical discourse analysis, metaphor, cognition, ideology

\section{INTRODUCTION}

Regarding discourse as a form of social practice, Critical Discourse Analysis (CDA) aims to explore the dialectical relationship between discourse, ideology and power. Instead of viewing language as transparent, CDA argues that discourse is socially constitutive as well as socially conditioned (Wodak \& Meyer, 2009) and imbued with ideological meaning. Although recent years have witnessed major progress in CDA, it faces severe criticism for its lack of attention to the cognitive aspects of communication and interlocutors. Therefore, scholars including O'Halloran (2003), Koller (2004), Chilton (2005), Hart (2010) advocate integrating Cognitive Linguistics with CDA in order to make the explanation and analysis more convincing. As a core part of Cognitive Linguistics, metaphor study is indispensable to this endeavor.

Since the publication of Lakoff and Johnson's Metaphors We Live By (1980) in which the Conceptual Metaphor Theory (CMT) was put forward, it has been widely recognized that metaphor is not only a linguistic phenomenon, but also an essential tool with which we come to understand the world. Our ordinary conceptual system in terms of which we both think and act is fundamentally metaphorical in nature. (Lakoff \& Johnson, 1980) Accordingly, the focus of metaphor study has been shifted to the cognitive aspects of metaphor such as its nature, comprehension, working mechanism, etc. However, metaphor is also social and functional. Metaphors may create realities for us, especially social realities. A metaphor may thus be a guide for future action, which will reinforce the power of the metaphor to make experience coherent. (Lakoff \& Johnson, 1980) A metaphor provides a particular perspective for perceiving and interpreting the world, thus underscoring a specific understanding of the reality while ignoring others. For CDA practitioners, a particular perspective presupposes ideological consideration. As is stated in Fairclough (1995a), ideology involves the representation of the world from the perspective of a particular interest, which indicates the important role that metaphor could play in CDA. Nevertheless, the synthesis of the two fields of study has been scarce by far. Mainstream CDA approaches (such as Fairclough's sociocultural approach, Wodak's discourse-historical approach) which combine grand social theories with linguistic ones tend to ignore the conceptual structures behind discourse, whereas CMT overlooks the ideological and social dimension of metaphor.

\section{Conceptual Metaphor Theory}

According to CMT, metaphor is not a matter of language but of thought. The essence of metaphor is understanding and experiencing one kind of thing in terms of another (Lakoff \& Johnson, 1980). In other words, metaphor is cross-domain mapping from the source domain to target domain, with the former typically referring to abstract and intangible concepts and the latter to concrete and tangible ones. In the metaphor TIME IS MONEY, we understand the abstract and intangible "time" which comprises the target domain with recourse to the concrete and tangible "money" which is the source domain. According to Kövecses (2010), our experiences with the physical world serve as a natural and logical foundation for the comprehension of more abstract domains.

Conceptual metaphor is different from metaphorical expressions which refer to linguistic expressions that are the surface realization of underlying conceptual metaphor. For instance, the same metaphor TIME IS MONEY can be realized in the following different expressions like "Hurry up, we're wasting time", "She invested a lot of time in learning English", "We'll take a cab to save time", etc. Linguistic metaphors are important because language provides 
important evidence for what the conceptual system that we use in thinking and acting is like since communication is based on the same system. (Lakoff \& Johnson, 1980)

One of the important features of metaphor is that cross-domain mapping is systematic. There are ontological correspondences according to which entities in the target domain correspond systematically to those in the source domain. In LIFE IS A JOURNEY, "person" corresponds to "traveler", "life state" to "location", "life purpose" to "journey destination", "difficulty" to "impediment to travel", etc. Once these correspondences are activated, we map our knowledge about entities in the source domain onto those in the target domain, resulting in epistemic correspondences. When a traveler comes across troubles during a journey, he may strive to overcome them and continue his journey. Or he may be discouraged and eventually give up. Once the knowledge of "journey" is mapped onto "life", we may infer that when facing difficulties in life, some people confront them and proceed to achieve their life goals while other people choose to evade them and abandon their dreams. Meanwhile, the mapping is also partial and selective. First, not all the experience about the source domain will be mapped to the target domain; second, only some aspects of the target domain will be involved in the mapping and highlighted. In LIFE IS A JOURNEY, we can find that important matters for a journey such as "travel agency", "luggage" are totally ignored.

CMT opposes the comparison theory which argues that the basis of metaphor is pre-existing similarities between the source domain and target domain. Instead, CMT claims that people's experience forms the basis of metaphor. Two irrelevant domains are correlated in the experience so that people use the experience of one domain to talk about the other, providing a new perspective for understanding. In TIME IS MONEY, although there are no objective similarities between time and money, the two are highly interconnected in daily life. Wages, communication fees, bank interests are paid against time. The result of metaphor is then that we can perceive the similarities between them: both could be spent, saved, wasted, etc. Hence Lakoff and Johnson (1980) contends that metaphor creates similarities rather than vice versa.

Because the purpose of CMT is to demonstrate that metaphor is pervasive in thought and action, it focuses on the conventional metaphors which are found to be ubiquitous in language in order to explore cognitive commonalities of human beings. The system of conventional conceptual metaphor is mostly unconscious, automatic, and used with no noticeable effort, just like our linguistic system and the rest of our conceptual system. (Lakoff, 1993) By investigating the conventionalized metaphorical expressions, Lakoff aims to find the correspondences between the source domain and target domain in conventional metaphors and then the conceptual structures stored in the long-term memory. However, at this point Lakoff meets with severe criticism. First, the reliability and representativeness of the language data used in CMT are challenged, because most of them are elicited or invented rather than naturally-occurring. As Sinclair (1991) cautions, intuitions and introspections about language can be unreliable when it comes to natural language use. Second, most data are isolated sentences without any context information and thus cannot reflect their real use in daily communication. Since the cross-domain mapping does not occur in vacuum, metaphors are usually hardly comprehensible if context is disregarded. (Ortony, 1993) For example, the metaphorical expression "the sun" in "Anthony is the sun" is ambiguous because of the various qualities (gloom-dispelling, warmth-giving, nourishing, etc) that the sun has and therefore open to diverse interpretations. Due to the important role that context plays in understanding metaphor use, there has been an empirical turn in metaphor study recently and discourse metaphor research begins to thrive. The discursive turn in CMT coincides with the cognitive turn in CDA, offering an exciting opportunity to promote interdisciplinary dialogues between them.

\section{INTEGRATING CDA WITH CMT}

CDA studies the dialectical relationship between discourse and society. According to van Dijk (2009), there is no direct relationship between discourse structures and social structures, with individual and social cognition mediating between them. Unfortunately, cognition is neglected in most CDA research, although CDA has made great progress in elucidating the social aspects concerning discourse production and comprehension. With the development of Cognitive Linguistics (especially metaphor study), more and more scholars begin to integrate CDA with CMT, giving birth to a new research field - Critical Metaphor Analysis.

Charteris-Black (2004) holds a similar opinion to van Dijk's, arguing that the choice of metaphor is governed by both individual and social resources. The former comprises mainly cognition, emotion, pragmatic and linguistic knowledge while the latter refers to ideological outlook, historical and cultural knowledge. CMT provides a better explanation of metaphor comprehension and its experiential basis but fails to answer the question why people prefer some metaphors to others in a particular context. As a result, an analysis of cognitive aspects of metaphor should be complemented with that of pragmatic ones.

The same notion can be communicated through different metaphors and the same metaphor may also be used in different ways according to the speaker's ideological perspective. (Charteris-Black, 2004) In examining news reports concerning Singapore's separation from the Federation of Malaysia in 1965, Wee (2001) finds that a recurring metaphor used to conceptualize the Singapore-Malaysia relationship is MARRIAGE - UNIFICATION IS MARRIAGE and SEPARATION IS DIVORCE. However, the MARRIAGE metaphor is employed very differently by the media of the two countries. Malaysian media tend to overtly map the marital roles: who the husband and wife are. Taking into account the power and territories of the two countries, Malaysia unquestionably takes the role of the husband and Singapore that of the wife (see Example 1). By contrast, the Singaporean media say nothing about the roles (see 
Example 2 and 3). Being specifically treated as the wife or husband carries political implications concerning dominance, strength and independence. (Wee, 2001) If Singapore is treated as the wife, it will be regarded as dominated and powerless, which is not in line with its political interest. That is why in Example 2 Singaporean media emphasize that it is a marriage of equals. Wee's research shows clearly that even when using the same metaphor, the speaker still has a choice in which aspects of the source domain may be mapped or hidden so as to achieve his communicative purpose.

Example 1:

I say if you marry a pretty girl and don't get on well with her, you've got to divorce her.

Example 2:

The Singapore advocates of merger see it as a natural progress... a marriage of equals.

Example 3:

This happy marriage was to go through bad times as events were to prove.

Metaphor plays a key role in the construction of social reality, for few concepts are semantically autonomous. Thus, conceptualization of the world relies greatly on metaphor. According to Fairclough (1995b), metaphors are socially motivated, different metaphors may correspond to different interests and perspectives and may have different ideological loadings. When we see the world with a particular metaphor, it then forms basis of our action. Therefore, once a new metaphor comes into being in our conceptual system, our perception of the world and behavior will change accordingly. When we view time metaphorically as money, we hope naturally that money could be the best compensation for our loss of time. Lakoff and Johnson (1980) highlight the importance of the metaphor by claiming that "the Westernization of cultures throughout the world is partly a matter of introducing the TIME IS MONEY metaphor into those cultures".

We understand the target domain with reference to the source domain when using a metaphor. But the two domains are so different in essence that the understanding is sure to be incomplete and partial. When certain characteristics of the target domain are highlighted, other aspects which are not consistent or relevant will be hidden. Hence, metaphor is not the objective reflection of reality, which is instead filtered through metaphor. Goatly (1997) argues that metaphor is not a mere reflection of a pre-existing objective reality but a construction of reality, through a categorization entailing the selection of some features as critical and others as noncritical.

In the mapping process of metaphor, Idealized Cognitive Model (ICM) is also mapped from the source domain to the target domain and plays a vital role in making inferences about the latter. (Lakoff, 1987) When understanding business in terms of war, people make use of their knowledge about war to reason about business. The fact that men play the dominant role in war entails the same role of men in the business field. Therefore, the metaphor helps to intensify the discrimination against women and position them as an out-group in business. Koller (2004) argues for a close link between the use of the WAR metaphor and the readership of business magazines, 90 percent of whom are actually males. The enforced usage of the metaphor strengthens the individual's sense of maleness and a predominantly male culture. (Wilson, 1992)

The point that metaphor creates similarities indicates diversified perspectives are characteristic of metaphor, the power of which lies in its construction of similarities. With the power, people can interpret social reality in accordance with their ideology. Although the interpretation is one of the many possibilities, dominant groups may take advantage of their social resources and make their metaphors the prevailing ones. So acceptance of their metaphors means the approval of their construction power. When their metaphors begin to be accepted by more and more people, individual cognition will turn into social cognition. Accordingly, the perspective provided by the metaphors would become the subconscious, which people can hardly feel, let alone challenge. The same point is mentioned in Lakoff and Turner (1989) when they state that metaphor that we rely on constantly, unconsciously, and automatically is so much part of us that it cannot be easily resisted, in large measure because it is barely even noticed.

\section{A CASE STUDY}

One of the big events in the auto industry in 2010 was Geely's (China's largest private-run car maker) acquisition of Volvo, which, as China's biggest overseas auto purchase, received extensive media coverage in China. At the end of March, Geely signed a deal to buy Volvo and the acquisition was completed in early August. Fifty Chinese news reports (altogether 94,955 characters) produced during this period from February to October 2010 were selected as the data for analysis. And each of the reports was examined in search of metaphors. Overall, these metaphors can be categorized into the following dominant themes: MARRIAGE (135 times), JOURNEY (113 times), HEALTH (62 times) and WAR (50 times).

MARRIAGE Metaphor

When the news about the acquisition arrived, most news reports described it as a marriage between Geely and Volvo. Since marriage is one of the most important events in one's lifetime, the metaphor highlights the importance of the acquisition. The marital roles are clearly identified in the metaphor, with Geely being the husband and Volvo the wife. Considering the size of the two companies, it seems reasonable for Volvo to be mapped as the husband. But Geely, although smaller, is the buyer and prospective parent company and thus more powerful. The mapping reflects the traditional view of marriage that the husband plays the dominant role in family affairs. The news is exciting because Chinese people are very proud that their domestic company has acquired such a famous car brand and takes full control 
of it. So mapping Geely as the husband is in accord with the readers' ideology. On the other hand, due to the huge difference in the size of the two companies, Geely, the husband, is typically described as a rural young man (农村青年) or a poor guy (贫民小子) while Volvo, the wife, as a princess (公主), an international superstar (国际巨星), a foreign beauty (洋美人儿) or a noble lady (贵族小姐) (Example 4). The story that a poor guy of humble birth marries a princess is a dream for most people, which only appears in fairy tales. Once it happens in reality, one should seize the chance. The metaphor by means of the fairy tale is highly persuasive, convincing the readers that it is a golden opportunity which can never be missed. Therefore, the metaphor implicitly expresses reporters' approval of the issue.

The mapping of the metaphor is so comprehensive that nearly every main aspect of marriage is involved. In Chinese culture, it is said that the mother-in-law's approval is vital to the success of a relationship and thus it is important to please her. In the reports, the labor union of Volvo is referred to as the mother-in-law (丈母娘) of Geely, highlighting the importance of the union in the deal (Example 5). In addition, the acquisition fee is seen as the bride price (彩礼), the government's permission as the marriage certificate (结婚证), the initial period after the buyout as the honeymoon (蜜 月).

Interestingly, when Li Shufu (boss of Geely) talks about new Volvo's independence, he abandons the MARRIAGE metaphor by claiming that Geely and Volvo are brothers instead of a father and son (Example 6). From the above, we can see that the choice of metaphor is not neutral but reflects the speaker's stance.

Example 4

被业内称为“贫民小子娶贵族小姐”的吉利收购沃尔沃收购案已进入倒计时。

The countdown has started for Geely's acquisition of Volvo, which insiders describe as "a poor guy is to marry a noble lady".

Example 5

作为吉利的“丈母娘”, 沃尔沃的工会显然是个难缠的主。

As Geely's mother-in-law, the labor union of Volvo is apparently hard to deal with.

Example 6

“未来吉利汽车与沃尔沃轿车是兄弟之间的关系，而不是父子之间的关系......”李书福表示。

"In the future, Geely and Volvo will be brothers instead of a father and son...", says Li Shufu.

JOURNEY Metaphor

The most frequent metaphorical expressions in this theme are “step” (步) (39 times) and “way” (道/路) (36 times). A business activity is typically viewed as a journey and each move taken during the process as a step. Taking a step forward means getting closer to the destination and is thus regarded as highly significant. If Geely does not take a step forward (原地踏步) or has difficulty in doing so (举步维艰), it means that Geely faces a serious problem (Example 7). Although the deal is lauded by most experts, they are also aware of the future challenges facing Geely by arguing that the acquisition is only the first step, implying more steps need to be taken.

As an important part of a journey, the concept "way" also plays a key role in the metaphor. Different ways signify various development directions of a company. Thus, it is argued that the deal in question shows that overseas acquisition is a possible way for the development of domestic car brands. Since it can help domestic companies approach the international market more quickly, it is also regarded as a shortcut (捷径) (Example 8). A smooth way makes the journey easy and comfortable while a rugged one imposes difficulties. So the painstaking and time-consuming acquiring process is mapped as a rugged way (道路坎坷). In the journey, the longer the way is, the more distant the destination is. Accordingly, Geely, which faces great challenges, has a long way to go. People may encounter barriers on the way and have difficulties in reaching the destination. Therefore, in order to take full advantage of the acquisition, Geely needs to “step across various barriers” (跨越障碍, overcome troubles, Example 9).

In addition, the business tends to be considered as a vehicle. For example, in the data Volvo is regarded as a huge ship (巨轮). The head of a company is viewed as a captain (船长) or a steersman (掌舵人), playing a key role in the development of the company (Example 10). At this point, the journey turns into a more specific voyage across sea (航 行). If the mission fails, the ship grounds in shallow water (搁浅).

Example 7

如果还是原地踏步，或者说越做越差，那么这些问题都是问题。

If Geely takes no step forward or even does worse, all these problems will remain.

Example 8

开拓国际汽车市场, 品牌收购将是一个捷径。

Acquisition of brands offers a shortcut (for Geely) to get access to the world auto market

Example 9

这表明当事方深知今后有多少分歧要弥合，有多少障碍要跨越。

This shows both parties are well aware of the abundant differences that they need to resolve and barriers that they should "step across".

Example 10

沃尔沃这艘漂浮在海中的巨轮, 或将迎来一位新的船长。 
Volvo, a huge ship floating on the sea, may have its new captain.

HEALTH Metaphor

The most common metaphorical expression in this type is “digest” (消化) (20 times). Geely's acquiring Volvo is described as a person eating food. Food can help keep people healthy, but too much food may cause indigestion, doing harm to health. Consequently, taking over such a big company, Geely runs the risk of indigestion. It is also a great challenge for Geely to digest (absorb, assimilate) Volvo's unique corporate culture which is so different from Geely's and the advanced technology which is far beyond Geely's capability. But if Geely can manage Volvo well, it will show that it has a good digestive ability. Overall, the DIGESTION metaphor in the news reports is employed to remind the readers of the difficulties in running Volvo (Example 11).

Another key expression is "blood" (血). In Chinese medicine, blood is one of three basic kinds of substance (the other two being 气 “gas” and 津液 “fluids other than blood”), which serve as the basis upon which the organs, tissues, and so forth function. (Yu, 1998) Because of its great importance to life, blood is considered as vital to company's survival. Therefore, if a company is weak, it needs blood transfusion (输血); and if a company is strong enough, it can donate blood to others. Considering Geely's relative small size, it is not realistic for it to donate blood to Volvo continuously. Instead, it is more practical for Geely to help Volvo to restore its own ability to form blood (造血) as quickly as possible (Example 12).

Furthermore, Volvo is often described as a person suffering from illness. In order to help Volvo regain health, illness of long standing (旧疾) needs to be diagnosed by feeling the pulse (把脉, a diagnostic method in traditional Chinese medicine). And the plan to help Volvo get out of trouble is viewed as a prescription (药方, Example 13). Meanwhile, the metaphor also carries the implication that it is a rare opportunity for Geely to acquire Volvo. Once the giant recovers, it is way beyond Geely's reach.

Example 11

缺乏全球化管理水平和其它不足可能让吉利难以消化沃尔沃。

A lack of global management skills and other shortcomings could make it tough for Geely to digest Volvo.

Example 12

收购成功后, 重要的不是输血, 而是恢复沃尔沃的造血功能, 早日扭亏为盈。

After the takeover, the important task is not to transfuse blood to Volvo, but to help Volvo to restore its own ability to form blood and return to profitability soon.

Example 13

在并购成功后, 李书福为沃尔沃扭亏为盈开出了第一剂药方。

After the acquisition, Li Shufu gave his first prescription for Volvo to turn losses into profits.

WAR Metaphor

As mentioned above, BUSSINESS IS WAR is a typical metaphor in business discourse, in which competitors are viewed as the enemy, competition as the battle, the market as the battlefield, the goal as the victory, etc. The metaphorical expression used the most is “strategy" (战略). Business decisions made by Geely are considered as military strategies. And it is said that Geely is not fighting itself, for it is backed by Chinese banks, local and central governments, which can be regarded as its allies (Example 14). In order to show how fierce competition is in car industry, "a hand-to-hand combat" (肉搏战) is employed. If the advantages of both Geely and Volvo can be integrated, a good coordinate battle (配合战) is highly expected. In addition, due to Geely's heroic performance, its boss Li Shufu is hailed as a warrior (勇士).

The WAR metaphor is so entrenched in our cognition that it has nearly become the standard way of talking about business, with many important features concerning business ignored. Though similarities arise between business and war, they are different in essence. In business, your rivals can never be defeated, for they always exist. Old rivals can be replaced by new ones very soon. Therefore, what you need to do is not get rid of them, but live with them. Furthermore, war has a devastating effect on human beings while business is expected to be a boon. Competition in business benefits the customers and the society as a whole and can also promote the development of the company itself. Thus, the WAR metaphor only focuses on the competitiveness and confrontation in business while ignoring the cooperative aspect and a possible win-win situation. The experiment conducted by Boers (1997) shows that with a different metaphor, people tend to consider business activities as cooperative, which may have a significant impact on the decision-making process.

Example 14

吉利不是一个人在战斗，其背后有国内银行、地方政府乃至中央政府部门的大力支持。

Backed by Chinese banks, local and central governments, Geely is not fighting alone.

Example 15

可以令其 (雅克布) 与熟悉中国市场的吉利打出漂亮的配合战。

Jacoby and Geely, which is familiar with Chinese market, can launch a nice coordinate battle.

Metaphor use in English news reports was also investigated in the study. On the whole, the acquisition did not have wide press coverage in the UK and US. Twenty English reports comprise the data (15,675 words). Three dominant 
metaphor themes are identified: JOURNEY (21 times), GAME (15 times) and WAR (8 times). The most frequent MARRIAGE metaphor in the Chinese reports is hardly employed while the JOURNEY and WAR metaphor are used rather similarly, with the former emphasizing the future development of both Geely and Volvo and the latter the competitiveness in the business world. However, there still exists significant difference. In Chinese reports, the agents in the two above-mentioned metaphors are generally either Geely or Volvo. But in English media, there are also many cases in which the agent changes into China (Examples 16 and 17), highlighting China's ambition to become an auto power. Therefore, the acquisition is not only regarded as a corporate matter but also relates to China's development strategy. The GAME metaphor is often used in a similar way to the WAR metaphor, focusing on the competition in business. What deserves attention is the more specific GAMBLE metaphor (5 times). In contrast to Chinese media's enthusiasm about the acquisition, English media express a more negative attitude to the takeover by the use of the GAMBLE metaphor (Example 18) in which luck plays an important role. Therefore, the acquisition is not considered as a sensible decision made by Geely, which is called an "upstart" in English reports, though acclaimed as a hero in Chinese ones. The GAMBLE metaphor clearly expresses reporters' disapproval of the deal.

Example 16

The acquisition underscores China's arrival as a force in the global car industry, as well as flagging up its ambition to become a big player on the world business stage.

Example 17

The purchase of one of Europe's most storied brands shows how China has emerged not just as the largest auto market by number of vehicles sold in the last year, but also as a country determined to capture market share around the globe.

Example 18

For Geely, acquiring Volvo is both an extraordinary statement of intent and a huge gamble.

\section{CONCLUSION}

CDA argues that the world we know is constructed through discourse, the analysis of which contributes to a better understanding of the reality as well as power relations. However, that construction can only be taking place in the minds of (interacting) individuals. (Chilton, 2005) In order to investigate how discourse impacts society, we need to know the cognitive processes involved because discourse maintains, influences and changes social reality through human mind. Metaphor research provides such a tool to fill the gap. Unfortunately, until recently metaphor largely escaped CDA practitioners' attention. The case study shows that the function of metaphor is two-fold: the first is cognitive, facilitating the understanding of one entity in terms of another; the second is pragmatic, serving the communicative purpose and showing the ideological stance, cultural stereotype and bias. The integration between the two research fields is beneficial to both. Addressing the cognitive aspects of discourse can enrich CDA analytic framework and render the interpretation more reasonable, while taking a critical discourse perspective helps to draw attention to the social and ideological dimension of metaphor.

\section{ACKNOWLEDGMENT}

This work was supported by a grant from Tianjin Municipal Education Commission (No. 20112205).

\section{REFERENCES}

[1] Boers, F. (1997). "No Pain, No Gain" in a Free Market Rhetoric: A Test for Cognitive Semantics? Metaphor and Symbol, 4 , 231-241.

[2] Charteris-Black, J. (2004). Corpus Approaches to Critical Metaphor Analysis. Basingstoke: Palgrave Macmillan.

[3] Chilton, P. (2005). Missing Links in Mainstream CDA: Modules, Blends and the Critical Instinct. In R. Wodak \& P. Chilton (Eds.), A New Agenda in (Critical) Discourse Analysis. Amsterdam: John Benjamins, 19-51.

[4] Fairclough, N. (1995a). Critical Discourse Analysis: The Critical Study of Language. London: Longman.

[5] Fairclough, N. (1995b). Media Discourse. London: Edward Arnold.

[6] Goatly, A. (1997). The Language of Metaphors. London: Routledge.

[7] Hart, C. (2010). Critical Discourse Analysis and Cognitive Science: New Perspectives on Immigration Discourse. Basingstoke: Palgrave Macmillan.

[8] Koller, V. (2004). Metaphor and Gender in Business Media Discourse: A Critical Cognitive Study. Basingstoke: Palgrave Macmillan.

[9] Kövecses, Z. (2010). Metaphor: A Practical Introduction (2nd edn.). Oxford: Oxford University Press.

[10] Lakoff, G. (1987). Women, Fire, and Dangerous Things: What Categories Reveal About the Mind. Chicago: University of Chicago Press.

[11] Lakoff, G. (1993). The Contemporary Theory of Metaphor. In A. Ortony (Ed.), Metaphor and Thought. Cambridge: Cambridge University Press, 202-251.

[12] Lakoff, G. \& M. Johnson. (1980). Metaphors We Live By. Chicago: University of Chicago Press.

[13] Lakoff, G. \& M. Turner. (1989). More than Cool Reason: A Field Guide to Poetic Metaphor. Chicago: The University of Chicago Press.

[14] Ning, Yu. (1998). The Contemporary Theory of Metaphor: A Perspective from Chinese. Amsterdam: John Benjamins. 
[15] O’Halloran, K. (2003). Critical Discourse Analysis and Cognition. Edinburgh: Edinburgh University Press.

[16] Ortony, A. (1993). Metaphor, Language and Thought. In A. Ortony (Ed.), Metaphor and Thought. Cambridge: Cambridge University Press, 1-18.

[17] Sinclair, J. (1991). Corpus, Concordance, Collocation. London: Oxford University Press.

[18] Van Dijk, T. A. (2009). Critical Discourse Studies: A Sociocognitive Approach. In R. Wodak \& M. Meyer (Eds.), Methods of Critical Discourse Analysis (2nd edn.) . London: Sage, 62-86.

[19] Wee, L. (2001). Divorce Before Marriage in the Singapore-Malaysia Relationship: The Invariance Principle at Work. Discourse and Society, 4, 535-549.

[20] Wilson, F. (1992). Language, Technology, Gender, and Power. Human Relations, 9, 883-904.

[21] Wodak, R \& Meyer, M. (2009). Critical Discourse Analysis: History, Agenda, Theory, and Methodology. In R. Wodak \& M. Meyer (eds.), Methods of Critical Discourse Analysis (2nd edn.). London: Sage, 1-33.

Song Guo received his M.A. in Linguistics from Wuhan University of Technology, China in 2004. He is a lecturer at Tianjin University of Commerce, Tianjin, China, where he teaches English language and linguistics in the School of Foreign Languages. His main interest is (critical) discourse analysis and sociolinguistics. 